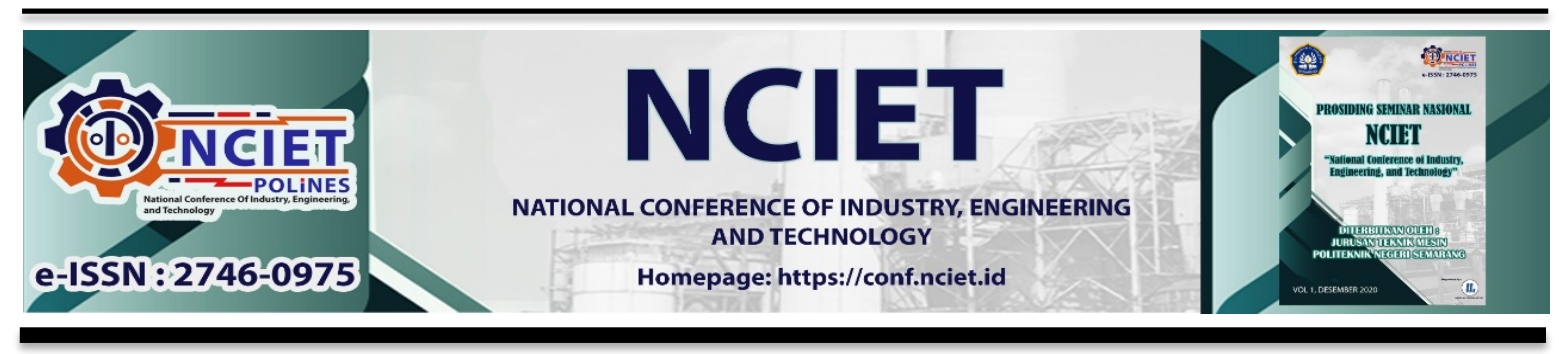

Prosiding Seminar Nasional NCIET Vol.1 (2020) B118-B125

$1^{\text {st }}$ National Conference of Industry, Engineering and Technology 2020,

Semarang, Indonesia.

\title{
OPTIMASI UNJUK KERJA BOILER DENGAN STUDI KASUS PADA SCREW AIR COMPRESSOR INGERSOLL RAND MM45 ROTARY
}

\author{
Al A'raaf Mutiara Darussalam*, Dwiana Hendrawati \\ Jurusan Teknik Mesin, Politeknik Negeri Semarang \\ J1. Prof. H. Soedarto, S.H., Tembalang, Semarang, 50275 \\ *E-mail: alaraafmd@gmail.com
}

\begin{abstract}
Abstrak
Di PPSDM MIGAS Cepu udara atau gas bertekanan berperan penting bagi kelancaran operasi sistem. Hal ini dikarenakan udara atau gas bertekanan digunakan sebagai penunjang operasi sistem di kilang, boiler dan softerner, bahkan untuk keperluan proses pengolahan. Untuk memperoleh udara atau gas bertekanan tersebut digunakanlah kompresor jenis pemindah positif Screw Air Compressor. Untuk menjaga optimasi kinerja kompresor maka dibutuhkan pengoperasian dan pemeliharaan sesuai dengan prosedur yang benar agar terhindar dari gangguan selama operasi berlangsung. Hal yang harus diperhatikan selama kompresor beroperasi adalah tekanan kerja. Tekanan kerja maksimum dari Screw Air Compressor Ingersoll Rand MM45 Rotary yaitu 0,85 MPa, sehingga selama beroperasi tekanan kompresor tidak boleh melebihi batas tersebut. Dengan melaksanakan pengoperasian sesuai dengan Standart Operating Procedure dan perawatan sesuai dengan Maintenance Manual yang berlaku, kompresor yang sudah lama berada di PPSDM MIGAS Cepu masih dapat digunakan untuk mendukung performa Boiler.
\end{abstract}

Kata Kunci: kompresor; optimasi; perawatan; perbaikan; proses

\section{PENDAHULUAN}

Di industri migas udara atau gas bertekanan berperan penting bagi kelancaran operasi suatu peralatan atau mesin. Dimana udara atau gas bertekanan digunakan sebagai penunjang operasi sistem seperti pada mesin pneumatic, pompa ataupun turbin gas. Untuk memperoleh udara atau gas bertekanan tersebut diperlukan suatu peralatan yaitu kompresor. Jenis kompresor sangat beragam sesuai dengan kebutuhan yang diperlukan oleh industri masingmasing. Dimana di Pusat Pengembangan Sumber Daya Manusia Minyak dan Gas Bumi (PPSDM MIGAS) Cepu menggunakan kompresor jenis pemindah positif yaitu kompresor screw untuk memenuhi kebutuhan system terutama kilang dan boiler. 
Pentingnya keberadaan kompresor maka kondisi kompresor harus dalam keadaan baik, sehingga dapat meminimalisir terjadinya gangguan yang terjadi selama sistem beroperasi ataupun pada saat pemeliharaan.

Untuk mengatasi hal tersebut diperlukan adanya sistem pengoperasian sesuai dengan Standart Operating Procedure dan perawatan sesuai dengan Maintenance Manual yang berlaku. Salah satu parameter yang penting adalah tekanan kerja kompresor. Dimana sistem akan tetap aman beroperasi apabila tekanannya tidak melebihi batas.

\section{METODE PENELITIAN}

Selama proses penelitian, metode yang digunakan dalam pengumpulan data adalah sebagai berikut:

1. Observasi Data

Pengambilan data dilaksanakan dengan melakukan pengamatan langsung ke lapangan dengan didampingi pembimbing lapangan yang ada di Pusat Pengembangan Sumber Daya Manusia Minyak dan Gas Bumi Cepu.

2. Wawancara dan Diskusi

Melakukan wawancara ataupun diskusi bersama secara langsung dengan pembimbing lapangan di Pusat Pengembangan Sumber Daya Manusia Minyak dan Gas Bumi Cepu agar mendapatkan data dan informasi yang diperlukan yang akurat.

3. Studi Literatur

Penulis mendapatkan pengetahuan yang lebih luas dengan studi literatur dari berbagai buku referensi, e-book ataupun jurnal-jurnal dari internet guna menambah wawasan saat proses penyusunan.

Dengan metode diatas dapat dibuat skema kerja yang dapat dilihat pada Gambar 1. 


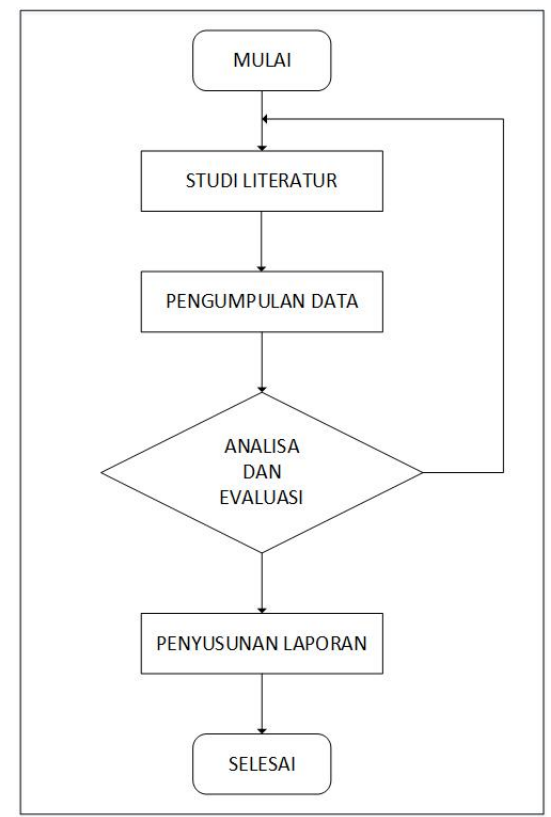

Gambar 1. Skema Kerja Penyusunan

\section{HASIL DAN PEMBAHASAN}

Screw Air Compressor memampatkan udara atau gasnya dengan putaran serempak gigigigi rotor atau roda gigi yang berputar dengan arah yang berlawanan dan saling berkaitan. Putaran serempak dan berlawanan inilah yang memindahkan dan memberikan tekanan kepada udara sepanjang alur rotor dari sisi masuk ke sisi keluar. Penampang kompresor dapat ditunjukan pada Gambar 2.

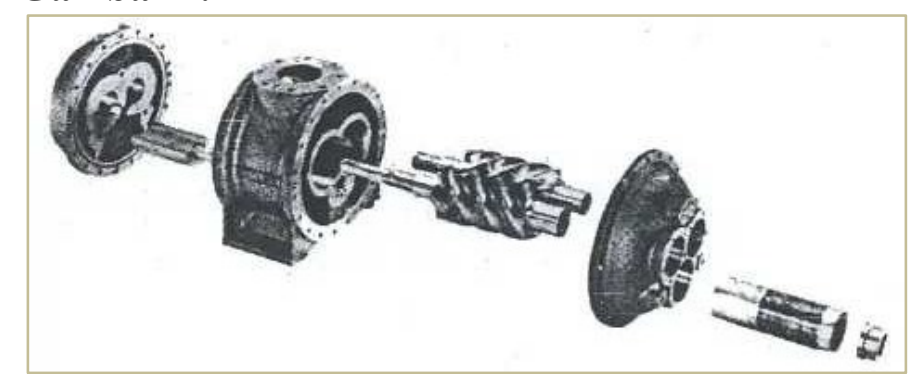

\section{Gambar 1. Penamang Kompresor Screw}

Sumber: (www.academia.edu $)$

Beberapa kelebihan dari penggunaan kompresor screw antara lain fluktuasi aliran sangat kecil. getaran (vibrasi) kecil karena tanpa ada bagian yang bergerak bolak-balik, ukurannya ringkas untuk daya yang sama dibanding kompresor torak, konstruksinya dan operasi mesin serta fasilitasnya sederhana, pemeliharaan dan pemeriksaan mesin dan peralatan lebih mudah, aliranya lebih kontinyu dibandingkan kompresor reciprocating.

Sedangkan kekurangan dari penggunaan kompresor screw yaitu, tidak dapat memberikan tekanan akhir yang tinggi efisiensi volumetrisnya rendah bila bagian-bagiannya 
kurang presisi, memerlukan perhatian lebih dalam sistem pelumasan screwnya.

Spesifikasi dari Screw Air Compressor yang digunakan di PPSDM MIGAS Cepu dapat dilihat dari Tabel 1.

Tabel 1. Spesifikasi Screw Air Kompresor

\begin{tabular}{|l|l|}
\hline Nama Alat & Ingersoll Rand Screw Air Compressor \\
\hline Pabrik Pembuat & Ingersoll Rand \\
\hline Model & MM45 ROTARY \\
\hline Type & Oil Injected \\
\hline Nomer Seri & 31701 -DJFG-AI-I \\
\hline Tahun Pembuatan & September 2008 \\
\hline Berat & $953 \mathrm{Kg}$ \\
\hline Dimensi & $1605 \times 1689 x 1696 \mathrm{~mm}$ \\
\hline Tekanan Kerja Maksimum & $0,85 \mathrm{Mpa}$ \\
\hline Kapasitas & $7,1 \mathrm{~m}$ /min \\
\hline Daya Maksimum & $45 \mathrm{KW}$ \\
\hline Jenis Pelumas & $\begin{array}{l}\text { SSR ULTRA COOLANT (Standard } \\
\text { Factory Fill) 5.28 gallon (20 liter) }\end{array}$ \\
\hline
\end{tabular}

Berdasarkan spesifikasi diatas, kompresor yang digunakan di PPSDM MIGAS Cepu memiliki tekanan kerja maksimum yaitu $0.85 \mathrm{MPa}$. Sehingga, kompresor akan tetap aman bekerja apabila masih dibawah batas temperatur kerja maksimum. Pengoperasian Screw Air Compressor sesuai dengan Standart Operating Procedure (SOP) yang berlaku yang pertama yaitu prosedur persiapan sebelum beroperasi dimana, sebelum kompresor beroperasi periksa level minyak pelumas pada subtank separator, periksa level pendingin tambahkan jika diperlukan, pastikan pengukur tekanan dan suhu dalam kondisi baik, katup untuk drain dalam kondisi tertutup rapat, katup isolasi utama dalam keadaaan terbuka, pastikan tidak ada peralatan mekanik atau lainnya di daerah operasi.

Pada saat, menutup sakelar pemutus utama, lampu "POWER" menunjukkan bahwa garis dan pengontrol tegangan telah tersedia untuk dilakukan start. Kemudian "UNLOAD" indikator akan menyala. Pastikan tidak ada baut yang longgar dan semua peralatan dalam kondisi baik dan siap untuk dijalankan.

Kedua yaitu prosedur pengoperasian (start up). Pada saat menyalakan kompresor pastikan kompresor pada kondisi bebas udara tekan, buang udara tekan terlebih dahulu. 
Kemudian pastikan bahwa lampu indikator power menyala dan terdapat tanda " READY TO START". Tekan tombol "START" . Kemudian Motor Penggerak akan berputar menggerakkan kompresor. Kemudian kompresor akan berputar dan akan load secara otomatis dan tekanan udara akan naik jika ada desakan udara yang cukup.

Prosedur yang ketiga yaitu selama beroperasi pastikan suhu temperatur udara discharge tidak boleh dari $109^{\circ} \mathrm{C}$ dan tekanan discharge lebih rendah dari $0.85 \mathrm{Mpa}$ (8.5 Bar) jika temperatur minyak pelumas dalam kondisi normal. Apabila muncul berbagai suara abnormal. Periksa jika terdapat suara abnormal pada rotor casing, dan bearing head pada kompresor.Apabila terjadi kebocoran minyak pelumas yang menyebabkan perbedaan tekanan muncul hingga 0.5 Bar atau lebih, bersihkan atau ganti elemen filter.

Keempat yaitu prosedur pemberhentian (shut down). Ketika terjadi shut down tekan tombol "UNLOADED STOP". Kompresor akan segera berputar unload dan kemudian kompresor akan unload \pm 7 detik dan kompresor akan berhenti. Buka saklar pemutus utama untuk menghentikan sistem.

Keadaan tidak terduga juga bisa saja terjadi atau disebut emergency stop sehingga terdapat prosedur yang harus dilaksanakan yaitu jika kondisi ini dibutuhkan, hentikan kompresor dengan segera atau jika ditekan tombol "UNLOADED STOP" dan kompresor tidak berhenti setelah 7 detik, tekanlah tombol "EMERGENCY STOP”. Buka saklar pemutus utama.

Selain cara pengoperasian yang harus sesuai dengan Standart Operating Procedure $(S O P)$, hal lain yang harus diperhatikan yaitu pemeliharaan perkala dari kompresor harus sesuai dengan Maintenance Manual yang berlaku. Hal ini bertujuan untuk mencegah terganggunya proses produksi di kilang karena kerusakan yang terjadi, menjaga kondisi kompresor agar tidak cepat menurun, mengetahui kerusakan sedini mungkin, mencegah kerusakan yang lebih parah dan memperpanjang usia pakai kompresor.

Berikut merupakan Pemeliharaan Screw Air Compressor sesuai dengan Maintenance Manual yang berlaku.

a. Pemeliharaan Harian

Tabel 2. Pemeliharaan Harian

\begin{tabular}{|l|l|}
\hline Komponen yang Diperiksa & \multicolumn{1}{c|}{ Cara Pemeriksaan } \\
\hline Pemeriksaan Kebocoran & Periksa apakah ada kebocoran pada saluran \\
Minyak Pelumas & minyak pelumas, perbaiki jika ada yang \\
\hline
\end{tabular}




\begin{tabular}{|l|l|}
\hline & rusak. \\
\hline Pemeriksaan tekanan dan & $\begin{array}{l}\text { Periksa apakah jarum manometer dapat } \\
\text { bergerak secara halus dan jarum menunjuk } \\
\text { angka nol (atau mendekati nol) bila tekanan } \\
\text { dalam tangki adalah nol. }\end{array}$ \\
\hline $\begin{array}{l}\text { Pemeriksaan vibrasi pada } \\
\text { motor dan kompresor. }\end{array}$ & $\begin{array}{l}\text { Periksa apakah putaran motor masih dalam } \\
\text { batas yang diperbolehkan. Jika melebihi atur } \\
\text { kecepatan motor sesuai ketentuan. }\end{array}$ \\
\hline $\begin{array}{l}\text { Drain vessel dan isolation } \\
\text { valve per shift. }\end{array}$ & $\begin{array}{l}\text { Periksa kapasitas vessel, jika berlebih atur } \\
\text { dengan menggunakan valve. }\end{array}$ \\
\hline
\end{tabular}

b. Pemeliharaan Mingguan

Tabel 3. Pemeliharaan Mingguan

\begin{tabular}{|l|l|}
\hline Komponen yang Diperiksa & \multicolumn{1}{c|}{ Cara Pemeriksaan } \\
\hline Peparator. & $\begin{array}{l}\text { Periksa setiap eleman dengan teliti, bersihkan } \\
\text { dari kotoran yang ada. }\end{array}$ \\
\hline Periksa filter udara delta P & $\begin{array}{l}\text { Jika udara yang masuk ke kompresor } \\
\text { berkurang periksa saringan isap, } \\
\text { kemungkinan tersumbat kotoran. Bersihkan } \\
\text { dengan sikat atau dengan zat pencuci yang } \\
\text { netral, jika terlalu kotor gantilah dengan yang } \\
\text { baru. }\end{array}$ \\
\hline Periksa level minyak pelumas. & $\begin{array}{l}\text { Jagalah agar permukaan minyak pelumas ada } \\
\text { dalam batas-batas yang ditentukan seperti } \\
\text { terlihat pada pengukur permukaan. } \\
\text { Tambahkan minyak jika permukaan sudah } \\
\text { mencapai batas terendah. }\end{array}$ \\
\hline
\end{tabular}

c. Pemeliharaan Bulanan (1000 Jam)

Tabel 4. Pemeliharaan Bulanan (1000 Jam)

\begin{tabular}{|l|l|}
\hline Komponen yang Diperiksa & \multicolumn{1}{|c|}{ Cara Pemeriksaan } \\
\hline Cek Temperatur Sensor & Periksa dengan menggunakan termometer. \\
\hline Penggantian Minyak & Ganti Food Grade Coolant (jika digunakan) \\
\hline
\end{tabular}




\begin{tabular}{|l|l|}
\hline Pelumas & $\begin{array}{l}\text { untuk penggunaan pertama dan } 6 \text { bulan untuk } \\
\text { pergantian seterusnya. }\end{array}$ \\
\hline Periksa kondisi selang & $\begin{array}{l}\text { Periksa apakah ada kerusakan pada selang atau } \\
\text { tidak dan bersihkan dari kotoran yang } \\
\text { menempel. }\end{array}$ \\
\hline
\end{tabular}

d. Pemeliharaan 3 Bulanan (2000 Jam)

Tabel 5. Pemeliharaan 3 Bulanan (2000 Jam)

\begin{tabular}{|l|l|}
\hline Komponen yang Diperiksa & \multicolumn{1}{|c|}{ Cara Pemeriksaan } \\
\hline $\begin{array}{l}\text { Menganti filter element } \\
\text { minyak pelumas. }\end{array}$ & $\begin{array}{l}\text { Ganti dengan yang baru agar kualitas minyak } \\
\text { tetap terjaga. }\end{array}$ \\
\hline $\begin{array}{l}\text { Pemeriksaan kualitas } \\
\text { minyak pelumas. }\end{array}$ & $\begin{array}{l}\text { Dengan pengujian kadar minyak pelumas } \\
\text { dengan tester indikator. }\end{array}$ \\
\hline $\begin{array}{l}\text { Analisa getaran-getaran } \\
\text { yang timbul. }\end{array}$ & $\begin{array}{l}\text { Pemeriksaan secara visual dengan } \\
\text { pengecekan secara langsung. }\end{array}$ \\
\hline $\begin{array}{l}\text { Pemeriksaan kelurusan } \\
\text { kopling(coupling aligment }) .\end{array}$ & $\begin{array}{l}\text { Dengan menggunakan Straight Edge atau } \\
\text { Diel Indicator. }\end{array}$ \\
\hline
\end{tabular}

e. Pemeliharaan 5 Bulanan (4000 Jam)

Tabel 6. Pemeliharaan 5 Bulanan (4000 Jam)

\begin{tabular}{|l|l|}
\hline Komponen yang Diperiksa & \multicolumn{1}{c|}{ Cara Pemeriksaan } \\
\hline $\begin{array}{l}\text { Bersihkan scavange screen and } \\
\text { orifice. }\end{array}$ & Bersihkan dari kotoran yang menempel. \\
\hline Bersihkan coolant cores. & Bersihkan dari kotoran yang menempel. \\
\hline Ganti filter udara. & Ganti dengan yang baru \\
\hline
\end{tabular}

f. Pemeliharaan Tahunan (8000 Jam)

Tabel 7. Pemeliharaan Tahunan (8000 Jam)

\begin{tabular}{|l|l|}
\hline Komponen yang Diperiksa & \multicolumn{1}{c|}{ Cara Pemeriksaan } \\
\hline Penggantian Minyak & Ganti Ultra coolant (jika digunakan) untuk \\
Pelumas & $\begin{array}{l}\text { pergantian pertama dan 2 tahun untuk } \\
\text { pergantian berikutnya. }\end{array}$ \\
\hline Penggantian Kontakor & Ganti kontaktor motor starter. \\
\hline
\end{tabular}


g. Pemeliharaan 5 tahunan

Setiap lima tahun sekali akan dilaksanakan Overhoul yaitu pemeliharaan secara menyeluruh semua elemen yang ada di kompresor.

Dengan pengoperasian dan pemeliharaan sesuai dengan prosedur yang berlaku maka kompresor akan terhindar dari gangguan yang akan mengganggu operasi sistem. Sehingga kompresor dapat bekerja optimal untuk menunjang kinerja kilang maupun boiler yang ada di PPSDM MIGAS Cepu.

\section{KESIMPULAN}

Keberadaan Screw Air Compressor Ingersoll Rand MM45 Rotary di PPSDM MIGAS Cepu sangatlah penting karena menghasilkan udara bertekanan yang digunakan untuk menunjang operasi pada softener, boiler maupun kilang. Sehingga dengan pengoperasian sesuai dengan Standart Operating Procedure dan pemeliharaan sesuai dengan Maintenance Manual yang berlaku, kompresor yang berada di PPSDM MIGAS Cepu masih dapat digunakan dengan optimal untuk memenuhi kebutuhan boiler. Untuk proses perawatan yang lebih optimal diperlukan adanya kartu kendali perawatan sehingga informasi data-data yang dihasilkan akan lebih akurat agar lebih mudah untuk monitoring pendeteksi gangguan yang lebih tanggap.

\section{DAFTAR PUSTAKA}

Brown, Royce N. 1997. Compression Selection and Sizing Second Edition. Houston: Gulf Publishing Company.

Ir. Sularso, MSME dan Prof. Dr. Haruo Tahara, 1983. Pompa dan Kompresor. Jakarta: PT Pradnya Paramita.

Majumdar, S. R. 1996. Pneumatic Systems: Principles And Maintenance. Tata McGrawHill Education.

Pillis, Joseph W., and Milton W. Garland. 1992. Oil Pressure Maintenance For Screw Compressor. U.S. Patent No. 5,134,856.

Sularso, Tahara, 1996. Pompa dan Kompresor: Pemilihan, Pemakaian dan Pemeliharaan. Jakarta: PT Pradnya Paramita.

Sutjiatmo, Indera Nurhadi, 1981, Kompresor I: Departemen Pendidikan dan Kebudayaan Direktorat Pendidikan Menengah Kejuruan. 